\title{
Urinary Tract Infections in the Emergency Department: Which Antibiotics are Most Appropriate?
}

\author{
İbrahim Toker', Turgay Yılmaz Kılıç', Şükran Köse², Murat Yeşilaras'1, Orkun Ünek1', Serkan Hacar ${ }^{1}$, Ayşin Kılınç Toker \\ 'Department of Emergency Medicine, Tepecik Training and Education Hospital, İzmir, Turkey \\ 2Department of Infectious Diseases and Clinical Microbiology, Tepecik Training and Education Hospital, İzmir, Turkey
}

\begin{abstract}
Aim: Urinary tract infections (UTIs) are frequently seen and also empirically treated in the emergency department (ED). It is known that the antimicrobial resistance of uropathogens is increasing worldwide. Because geographical location plays an important role in antimicrobial resistance and can be used as a guide for treatment, regional studies are particularly important. The aim of this study is to analyze the urine cultures performed at our ED.

Materials and Methods: We investigated the medical records of 4,493 patients who were requested to give urine samples for culture at the ED of the Tepecik Training and Research Hospital between 2010 and 2014.

Results: In our study, $47.3 \%$ cultures were positive, and the most frequent microorganism was found to be Escherichia coli (E. coli) (66.7\%). Trimethoprim/sulfamethoxazole (TMP-SMX) and ciprofloxacin resistance rates were detected as $44.8 \%$ and $36.8 \%$, respectively; further, nitrofurantoin and fosfomycin resistance rates were detected as $13.3 \%$ and $7.6 \%$, respectively. The relationship of nitrite positivity with the reproduction of pathogens was found to be stronger than that of leukocyte esterase (LE).

Conclusion: For our region, for the empirical treatment of uncomplicated UTIs, fosfomycin and nitrofurantoin must be considered as the first-line agents. Because of the increasing ratio of antibiotic resistance, urinary culture samples must be arranged for in the ED itself where administering first-line treatment has mostly been initiated.
\end{abstract}

Keywords: Urinary tract infection, emergency medicine, antibiotic resistance

\section{Introduction}

The types of urinary tract infections (UTIs) presented to the emergency department (ED) in a clinic vary from simple cystitis to urosepsis (1).

The diagnosis of a UTI is done via urinary culture analysis, which can reveal a significant reproduction of bacteria (2). UTIs are classified by localization (upper/lower), clinical properties (complicated/ uncomplicated), or source (community acquired/nosocomial) (3). The foremost pathogen in community-acquired UTIs is E. coli, followed by Klebsiella spp., Proteus mirabilis, Enterococcus spp., and Pseudomonas aeruginosa; however, for nosocomial infections, the expected pathogen is generally related to the urinary catheter, and the patient's own flora is the culprit $(4,5)$. These classifications are used in order to choose the treatment method and duration (6).

In the guidelines of Infectious Diseases Society of America (IDSA) published in 2011, because of increasing antibiotic resistance, great- er emphasis has been put on choosing the proper antibiotic; therefore, it becomes more important to understand changes in regional antibiotic resistances $(3,7)$.

The aim of this study is to analyze the urine cultures performed at our ED and define the antimicrobial resistance rates for our region.

\section{Materials and Methods}

\section{Study design and setting}

This study was a retrospective review of adult patients with a positive urine culture between January 1, 2010 and December 31, 2014, in the ED of the Tepecik Training and Research Hospital-a tertiary hospital. Local ethics committee approval was obtained.

\section{Selection of participants}

By tracing the electronic health record, the urinary cultures received from predetermined patients above 18 years old were careful- 
ly studied. Among these patients, the ones whose culture and antibiogram results could not be obtained were excluded.

\section{Methods and measurements}

The demographic data of patients, their urinalysis, microorganisms which reproduced in their urine cultures, antibiogram results, accompanying diseases, history of urinary catheterization, method how the sample was obtained (catheter or mid-flow urine), and the outcomes were recorded.

Complete urine analysis was semi-quantitatively obtained using the $\mathrm{H} 800$ analyzer (Dirui Industrial Co. Ltd., China) and $\mathrm{H} 10-800$ strips (Dirui Industrial Co. Ltd., China). Test results that were negative (-) and trace (+/-) for leukocyte esterase (LE) were accepted as negative.

When bacteria $>10^{5} \mathrm{cfu} / \mathrm{mL}$ were reproduced in the urine culture, the result was considered positive. Isolated bacteria forms were conventionally defined. Isolates that were not conventionally identified were then defined by using a fully automated identification and antibiogram device (VITEK 2 compact, bioMérieux, France). The presence of more than two isolates at a concentration $\geq 10^{4} \mathrm{cfu} / \mathrm{mL}$ was considered as contamination.

\section{Statistical analysis}

For data analysis, Statistical Package for the Social Sciences (IBM SPSS Statistics Armonk, NY, USA) version 22 was used. Qualitative data were defined as the number of observations and percentage, while quantitative ones were represented as interquartile range (IQR) and minimum-maximum values. To compare the qualitative data, the chi-square test was used. For understanding the effect of LE and nitrite positivity on reproduction, the odds ratio (multinominal logistic regression) was considered for analyzing the mean modality. Values of $p<0.05$ were accepted to be statistically significant for a confidence interval of $95 \%$.

\section{Results}

During the 5-year period under consideration, 882,997 adult patients were admitted to the ED, and 4,493 patients were asked to provide a urine sample for culture. Because of getting no results, 80 samples were excluded; therefore, the research was carried out with 4,413 urine cultures.

Among the group who was asked to give a urine culture, $51.9 \%$ were female. The general median age was 66 years (IQR=32; min: 18; max: 114): the median age of men was 68 years (IQR: 26 ; min: 18; max: 97), whereas women had a median age of 63 years (IQR: 40; min: 18; max: 114). For all the cases, concomitant diseases were listed (Table 1).

In 2,585 urinary culture samples, bacteria reproduction was observed, but $11.3 \%$ ( $n=497)$ samples were considered as contamination. This contamination was more frequent in women $(n=301$, $13.1 \%)$ than men $(n=196,9.2 \%)$. As a result, 2,088 (47.3\%) cases were accepted as culture-positive UTIs.

In our study, 91\% microorganisms that reproduced in the culture were gram-negative bacilli; $7.5 \%$, gram-positive cocci; and $0.7 \%$, yeasts. Microorganism identities and their antimicrobial resistance frequencies are listed in Table 2 and 3.

Four of the top frequently prescribed antibiotics and their resistance rates are shown in Figure 1.

Here, 1,311 (29.7\%) urine samples were obtained by employing urinary catheterization in the ED, and $1.8 \%$ samples were obtained
Table 1. Concomitant diseases

\begin{tabular}{|l|c|}
\hline Concomittant diseases & n (\%) \\
\hline Malignancy & $765(17.3)$ \\
\hline Diabetes & $572(13)$ \\
\hline Acute Renal Failure & $380(8.6)$ \\
\hline Chronic renal failure & $356(8.1)$ \\
\hline Cerebrovascular Diseases & $245(5.6)$ \\
\hline Alzheimer's Disease & $223(5.1)$ \\
\hline Urolithiasis, nephrolithiasis & $191(4.3)$ \\
\hline Benign Prostate Hypertrophy & $162(3.7)$ \\
\hline Epilepsy & $111(2.5)$ \\
\hline Kidney Transplantation & $57(1.3)$ \\
\hline Parkinson's disease & $41(0.9)$ \\
\hline Immobile patients & $15(0.3)$ \\
\hline Hypertension & $649(14.7)$ \\
\hline Chronic obstructive pulmonary disease & $132(3)$ \\
\hline Heart failure & $184(4.2)$ \\
\hline Liver Cirrhosis & $40(0.9)$ \\
\hline AIDS & $3(0.1)$ \\
\hline
\end{tabular}

Table 2. Uropathogen microorganisms reproduced in urine cultures

\begin{tabular}{|l|c|}
\hline Uropathogen microorganism & $\mathbf{n}(\%)$ \\
\hline Escherichia coli & $1392(66.7)$ \\
\hline Klebsiella pneumoniae & $150(7.2)$ \\
\hline Coagulase-negative staphylococcus & $138(6.6)$ \\
\hline Pseudomonas aeruginosa & $84(4)$ \\
\hline Proteus mirabilis & $70(3.4)$ \\
\hline Enterococcus faecalis & $66(3.2)$ \\
\hline Staphylococcus aureus & $43(2.1)$ \\
\hline Klebsiella oxytoca & $26(1.2)$ \\
\hline Candida spp. & $17(0.8)$ \\
\hline Acinetobacter baumannii & $8(0.4)$ \\
\hline Enterobacter aerogenes & $7(0.3)$ \\
\hline Others* & $87(4.2)$ \\
\hline Total & $2088(100)$ \\
\hline $\begin{array}{l}\text { *Citrobacter freundii, Enterobacter cloacae, Stenotrophomonas maltophilia, Proteus vul- } \\
\text { garis, Morganella morganiii Streptococus pyogenes, Enterecoccus faecium, Providencia } \\
\text { rettgeri, Serratia marcescens, Citrobacter koseri, Salmonella spp., Streptococus viridans, } \\
\text { Streptococcus spp., Providencia stuartii, Enterobacter spp., Enterococcus gallinarum, } \\
\text { Corynebacterium spp., Streptococcus mitis }\end{array}$ \\
\hline
\end{tabular}

from urine catheters, which were already present. The frequency of contamination was almost the same with the patients who did not have a urinary catheter.

Further, $23.7 \%$ patients who had been asked to give a urine culture were hospitalized, and $19.8 \%$ were ICU admissions. 
Table 3. Resistance ratios of uropathogen microorganisms to antimicrobial agents

\begin{tabular}{|l|c|c|c|}
\hline Antimicrobial Agents & Total \% (n) & Female \% & Male \% \\
\hline Levofloxacin & $45.7(127)$ & 32.3 & 58.5 \\
\hline Trimethoprim-sulfamethoxazole & $44.8(1743)$ & 40.6 & 50.5 \\
\hline Cefuroxime & $37.9(596)$ & 33 & 44.7 \\
\hline Ciprofloxacin & $36.8(1694)$ & 30.7 & 44.9 \\
\hline Amoxicillin-clavulanate & $36.2(1207)$ & 29.2 & 46.1 \\
\hline Cefixime & $35.6(402)$ & 28.5 & 45.5 \\
\hline Ceftriaxone & $32.6(1397)$ & 26.3 & 41.6 \\
\hline Extended-spectrum & $14.3(1916)$ & 12.2 & 17.1 \\
\hline beta-lactamases & & & \\
\hline Nitrofurantoin & $13.3(1135)$ & 11.0 & 16.6 \\
\hline Fosfomycin & $11.8(1684)$ & 10.7 & 13.3 \\
\hline Imipenem & $7.6(1344)$ & 5.8 & 10.1 \\
\hline Vancomycin & $3.4(1160)$ & 2.1 & 5.0 \\
\hline Ertapenem & $1.9(52)$ & 5.3 & 0 \\
\hline & $1.6(980)$ & 1.4 & 1.9 \\
\hline
\end{tabular}

Table 4. Antimicrobial agents' resistance ratios among gender

\begin{tabular}{|c|c|c|c|c|}
\hline & & \multicolumn{2}{|c|}{ Gender } & \multirow[b]{2}{*}{$\mathbf{p}^{*}$} \\
\hline & & Female, n (\%) & Male, n (\%) & \\
\hline \multirow{2}{*}{$\begin{array}{l}\text { Nitrofurantoin } \\
(\mathrm{n}=1135)\end{array}$} & Susceptible & 591 (89\%) & 393 (83.4\%) & \multirow{2}{*}{0.007} \\
\hline & Resistant & 73 (11\%) & $78(16.6)$ & \\
\hline \multirow{2}{*}{$\begin{array}{l}\text { TMP-SMX } \\
(n=1743)\end{array}$} & Susceptible & 597 (59.4\%) & 365 (49.5\%) & \multirow{2}{*}{$<0.001$} \\
\hline & Resistant & 408 (40.6\%) & 373 (50.5\%) & \\
\hline \multirow{2}{*}{$\begin{array}{l}\text { Ciprofloxacin } \\
(n=1694)\end{array}$} & Susceptible & 669 (69.3\%) & 401 (55.1\%) & \multirow{2}{*}{$<0.001$} \\
\hline & Resistant & 297 (30.7\%) & 327 (44.9\%) & \\
\hline \multirow{3}{*}{$\begin{array}{l}\text { Fosfomycin } \\
(n=1344)\end{array}$} & Susceptible & 742 (94.2\%) & 500 (89.9\%) & \multirow{3}{*}{0.004} \\
\hline & Resistant & $46(5.8 \%)$ & $56(10.1 \%)$ & \\
\hline & Resistant & $214(26.3 \%)$ & 242 (41.6\%) & \\
\hline
\end{tabular}

The resistance ratio of the antibiotics, which are mostly empirically chosen, are listed in Table 4.

The relationship between urinary LE levels, nitrite positivity levels, and their relationship with respect to reproduction in urine cultures are listed in Table 5.

The resistance rates of $E$. coli strains against antimicrobial agents are listed in Table 6.

\section{Discussion}

In this research that is based on investigating the urinary cultures that were requested from the ED, we found that $47.3 \%$ samples were positive for microorganism reproduction, and the most frequent species was E. coli. Nitrite positivity in urine has a more powerful effect on the positivity of LE.
Table 5. Relationship of leukocyte esterase and nitrite positivity with reproduction in urine culture

\begin{tabular}{|c|c|c|c|c|}
\hline & & \multicolumn{2}{|c|}{ Reproduction in urine culture } & \multirow{2}{*}{$\begin{array}{c}\text { OR } \\
(95 \% \mathrm{Cl})\end{array}$} \\
\hline & & Negative (n) & Positive (n) & \\
\hline \multirow{4}{*}{$\begin{array}{l}\text { Leukocyte } \\
\text { esterase }\end{array}$} & Negative & 1370 & 1090 & \multirow[b]{2}{*}{$1.0(0.8-1.3)$} \\
\hline & $1+$ & 215 & 175 & \\
\hline & $2+$ & 229 & 265 & $1.5(1.2-1.8)$ \\
\hline & $3+$ & 258 & 397 & $1.9(1.6-2.3)$ \\
\hline \multirow{2}{*}{$\begin{array}{l}\text { Nitrite } \\
\text { positivity }\end{array}$} & Negative & 1574 & 906 & \\
\hline & Positive & 496 & 1021 & $3.6(3.1-4.1)$ \\
\hline \multirow{2}{*}{$\begin{array}{l}\text { Infection } \\
\text { sign* }\end{array}$} & Negative & 1117 & 529 & \\
\hline & Positive & 954 & 1398 & $3.1(2.7-3.5)$ \\
\hline
\end{tabular}

*Leukocyte esterase is least +1 or nitrite positivity, OR: odds ratio; $\mathrm{Cl}$ : confidence interval

Table 6. Resistance rates of E. coli strains against antimicrobial agents

\begin{tabular}{|l|c|}
\hline Antimicrobial agents & Resistance ratio \% (n) \\
\hline Levofloxacin & $52.7(55)$ \\
\hline Trimethoprim-sulfamethoxazole & $44.6(1277)$ \\
\hline Cefuroxime & $35.3(431)$ \\
\hline Ciprofloxacin & $38.6(1231)$ \\
\hline Amoxicillin-clavulanate & $33.6(923)$ \\
\hline Cefixime & $34.4(314)$ \\
\hline Ceftriaxone & $30.5(1032)$ \\
\hline Extended-spectrum beta-lactamases & $11.3(1916)$ \\
\hline Nitrofurantoin & $6.7(913)$ \\
\hline Piperacillin-tazobactam & $8.7(1224)$ \\
\hline Fosfomycin & $4.8(1061)$ \\
\hline Imipenem & $0.25(804)$ \\
\hline Vancomycin & $0(0)$ \\
\hline Ertapenem & $0.82(732)$ \\
\hline
\end{tabular}

Urinalysis is one of the most popularly used tests in the ED. Dipstick tests have taken the place of urinary microscopy because the use of the former is very easy and is cheaply available $(8,9)$. LE and nitrite positivity are stated to be good predictors in UTI diagnosis (10-12). In our study, the relationship between nitrite positivity and reproduction in cultures was found to be stronger than that with LE positivity. The $+2 /+3$ LE positivity in the odds ratios of urinalysis were 1.5 and 1.9 by the order of value, while nitrite positivity was noted as 3.6. However, urinary culture is still the primary standard for proving the existence of UTIs (2).

In the study by Arman al. (13), it was determined that the average age was $39.4 \pm 16.26$ years (16-82 years) among 400 patients who applied to first-grade health farms. In this research, the most frequent uropathogens were gram-negative microorganisms [ $E$. coli (62.8\%), Enterococcus spp. (3.2\%), Klebsiella pneumoniae (3.4\%), Pseudomonas aeruginosa (4\%), Proteus mirabilis (1.1\%), and Eneterobacter cloacae $(0.5 \%)]$, followed by coagulase-negative staphylococcus 


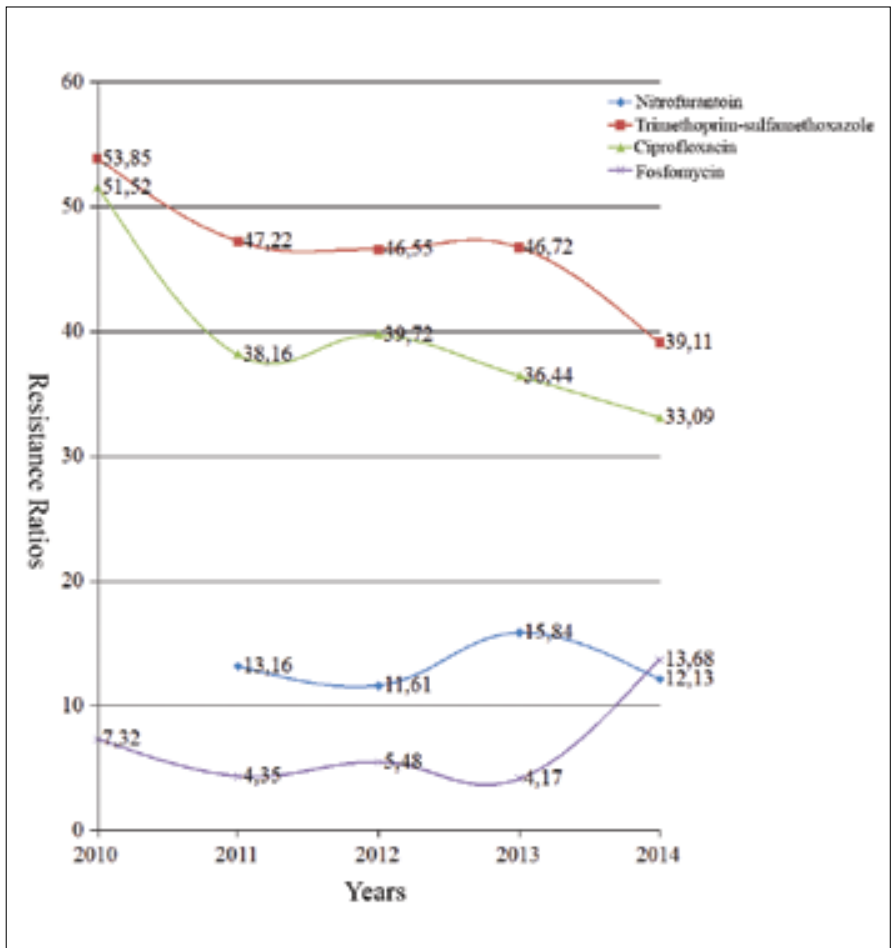

Figure 1. Resistance ratios for nitrofurantoin, trimethoprim-sulfamethoxazole, ciprofloxacin, and fosfomycin over several years

(24.5\%) (13). In our study, the majority of the isolated uropathogens were gram-negative bacilli (91.8\%). In agreement with the literature, the most frequent species was E. coli $(66.7 \%)$, followed by Klebsiella pneumoniae (7.2\%), coagulase-negative staphylococcus (6.4\%), Pseudomonas aeruginosa (4\%), Proteus mirabilis (3.4\%), and Enterococcus faecalis $(3.2 \%)$ in the order of frequency $(4,6)$.

The study by Bekeris et al. (14) was performed in 127 laboratories located in USA and Canada in which 14,739 urinary culture samples were collected, and the average contamination rate was noted as $15 \%$. In our study, the contamination rate was $11.3 \%$, which was notably excessive among women. Even though no disclosure form was present in our ED, the reason for the reduced contamination rate might be because the microbiology laboratory is located very close to the ED, so the samples reach the laboratory quickly, thereby reducing the risk of contamination.

In our study, it has been reported that even though having a downward trend from 2010 to 2014 (from $53.8 \%$ to $39.1 \%$ and from $51.5 \%$ to $33.1 \%$, respectively), TMP-SMX and ciprofloxacin resistance levels are still found to be high. Nitrofurantoin and fosfomycin are noted to have lower resistance levels, namely, $13.3 \%$ and $7.6 \%$, respectively.

In a retrospective research done by Guneysel et al. (15), among 274 patients who were diagnosed as having complicated UTI, the resistance rate of TMP-SMX was 34.4\%. In 2013, a meta-analysis was carried out by detecting the resistance of TMP-SMX for E. coli variables; the resistance percentage was determined as 47.8\% between 2008 and 2012 (16). In our study, the TMP-SMX resistance was found to be $44.8 \%$, with a slight reduction during the intervening period. There are other studies that have revealed a similar resistance ratio $(7,17-19)$.

Karlowsky et al. (20) showed the resistance ratio for ciprofloxacin as $2.5 \%$ in 1999. Sanchez et al. (21) used the data from 2000 to
2010 and showed that the resistance ratio of ciprofloxacin increased from $3 \%$ to $17 \%$. In the research by Arslan et al. (22), which was made throughout Turkey, ciprofloxacin resistance ratio with respect to $E$. coli isolates was found to be $17 \%$ in uncomplicated UTI patients, whilst it was $38 \%$ in complicated ones. In our study, we found that ciprofloxacin resistance reduced from $51 \%$ to $35 \%$, implying that ciprofloxacin resistance is still too high for our region.

Because of having a very low resistance ratio, fosfomycin is one of the most appropriate agents for treating uncomplicated cystitis (23). In our study, we determined that fosfomycin resistance among women was $5.8 \%$.

Nitrofurantoin resistance has been found to range between $2 \%$ and $28 \%$ in different studies. In our research, we found the resistance of nitrofurantoin to be $13.3 \%$. Because of this low resistance ratio, the use of nitrofurantoin seems to effectively fit for our region $(7,17-20,24)$.

\section{Study limitations}

Our study was limited due to its retrospective nature. Even though the presentations to the ED were mostly outpatients, the discrimination of infections (community-acquired or nosocomial) was not done. Because this study consisted of ED patients, it did not involve all the UTI cases. Also, some patients may have been discharged without being asked for a urine culture. In our study, the urine samples obtained from urinary catheters comprised $29.7 \%$ of the total; therefore, our research shows that the old with general debility may have been considered in a larger number as compared to other studies. For this reason, resistance ratios may be higher than expected.

\section{Conclusion}

In our study, we found that even though there is a slight reduction over the years, TMP-SMX and ciprofloxacin resistance ratios are still high. Because of lower resistance, fosfomycin and nitrofurantoin must be considered as the first choice for the treatment of lower UTIs.

Ethics Committee Approval: Ethics committee approval was received for this study from the ethics committee of Tepecik Training and Research Hospital (25.06.2014).

Informed Consent: In this retrospective study, informed consent form was not obtained, due to data abstracted from medical records.

Peer-review: Externally peer-reviewed.

Conflict of Interest: No conflict of interest was declared by the authors.

Financial Disclosure: The authors declared that this study has received no financial support.

\section{References}

1. Wilson ML, Gaido L. Laboratory diagnosis of urinary tract infections in adult patients. Clin Infect Dis 2004; 38: 1150-8. [CrossRef]

2. Takhar SS, Moran GJ. Diagnosis and management of urinary tract infection in the emergency department and outpatient settings. Infect Dis Clin North Am 2014; 28: 33-48. [CrossRef]

3. Best J, Kitlowski AD, Ou D, Bedolla J. Diagnosis and management of urinary tract infections in the emergency department. Emerg Med Pract 2014; 16: 1-24. 
4. Andrade SS, Sader HS, Jones RN, Pereira AS, Pignatari AC, Gales AC. Increased resistance to first-line agents among bacterial pathogens isolated from urinary tract infections in Latin America: time for local guidelines? Mem Inst Oswaldo Cruz. 2006; 101: 741-8. [CrossRef]

5. Tenke P, Kovacs B, Bjerklund Johansen TE, Matsumoto T, Tambyah PA, Naber KG. European and Asian guidelines on management and prevention of catheter-associated urinary tract infections. Int J Antimicrob Agents 2008; 31 (Suppl 1): S68-78. [CrossRef]

6. Hooton TM. Clinical practice. Uncomplicated urinary tract infection. N Engl J Med 2012; 366: 1028-37. [CrossRef]

7. Gupta K, Hooton TM, Naber KG, Wullt B, Colgan R, Miller LG, et al. International clinical practice guidelines for the treatment of acute uncomplicated cystitis and pyelonephritis in women: A 2010 update by the Infectious Diseases Society of America and the European Society for Microbiology and Infectious Diseases. Clin Infect Dis 2011; 52: e103-20. [CrossRef]

8. Lane DR, Takhar SS. Diagnosis and management of urinary tract infection and pyelonephritis. Emerg Med Clin North Am 2011; 29: 539-52. [CrossRef]

9. Nagurney JT, Brown DF, Chang Y, Sane S, Wang AC, Weiner JB. Use of diagnostic testing in the emergency department for patients presenting with non-traumatic abdominal pain. J Emerg Med 2003; 25: 363-71. [CrossRef]

10. Jones CW, Culbreath KD, Mehrotra A, Gilligan PH. Reflect urine culture cancellation in the emergency department. J Emerg Med 2014; 46: 71-6. [CrossRef]

11. dos Santos JC, Weber LP, Perez LR. Evaluation of urinalysis parameters to predict urinary-tract infection. Braz J Infect Dis 2007; 11:479-81. [CrossRef]

12. Van Nostrand JD, Junkins AD, Bartholdi RK. Poor predictive ability of urinalysis and microscopic examination to detect urinary tract infection. Am J Clin Pathol 2000; 113: 709-13. [CrossRef]

13. Arman D, Ağalar $C$, Dizbay $M$, Tunçcan ÖG, Keten DT, Aygün $G$, ve ark. Birinci basamak sağlık merkezlerinde toplum kökenli alt üriner sistem enfeksiyonları: Etkenler ve antimikrobiyal duyarlılıkları. Mediterr J Infect Microbes Antimicrobials 2012; 1: 1-8.
14. Bekeris $L G$, Jones $B A$, Walsh $M K$, Wagar EA. Urine culture contamination: a College of American Pathologists Q-Probes study of 127 laboratories. Arch Pathol Lab Med 2008; 132: 913-7.

15. Guneysel O, Onur O, Erdede M, Denizbasi A. Trimethoprim/sulfamethoxazole resistance in urinary tract infections. J Emerg Med 2009; 36: 338-41. [CrossRef]

16. Aykan SB, Ciftci IH. Antibiotic resistance patterns of Escherichia coli strains isolated from urine cultures in Turkey: a meta-analysis. Mikrobiyol Bul 2013; 47: 603-18. [CrossRef]

17. Khawcharoenporn T, Vasoo S, Ward E, Singh K. High rates of quinolone resistance among urinary tract infections in the ED. Am J Emerg Med 2012; 30: 68-74. [CrossRef]

18. Farajnia S, Alikhani MY, Ghotaslou R, Naghili B, Nakhlband A. Causative agents and antimicrobial susceptibilities of urinary tract infections in the northwest of Iran. Int J Infect Dis 2009; 13: 140-4. [CrossRef]

19. Kashef N, Djavid GE, Shahbazi S. Antimicrobial susceptibility patterns of community-acquired uropathogens in Tehran, Iran. J Infect Dev Ctries 2010; 4: 202-6. [CrossRef]

20. Karlowsky JA, Jones ME, Thornsberry C, Critchley I, Kelly LJ, Sahm DF. Prevalence of antimicrobial resistance among urinary tract pathogens isolated from female outpatients across the US in 1999. Int J Antimicrob Agents 2001; 18: 121-7. [CrossRef]

21. Sanchez GV, Master RN, Karlowsky JA, Bordon JM. In vitro antimicrobial resistance of urinary Escherichia coli isolates among U.S. outpatients from 2000 to 2010. Antimicrob Agents Chemother 2012; 56: 2181-3. [CrossRef]

22. Arslan H, Azap OK, Ergonul O, Timurkaynak F, Urinary Tract Infection Study G. Risk factors for ciprofloxacin resistance among Escherichia coli strains isolated from community-acquired urinary tract infections in Turkey. J Antimicrob Chemother 2005; 56: 914-8. [CrossRef]

23. Grigoryan L, Trautner BW, Gupta K. Diagnosis and management of urinary tract infections in the outpatient setting: a review. JAMA 2014; 312: 1677-84. [CrossRef]

24. Dash M, Padhi S, Mohanty I, Panda P, Parida B. Antimicrobial resistance in pathogens causing urinary tract infections in a rural community of Odisha, India. J Family Community Med 2013; 20: 20-6. [CrossRef] 